\title{
Short-Term Shareholders, Bubbles, And CEO Myopia
}

\author{
John Thanassoulis \\ University of Oxford
}

January 8, 2013

\begin{abstract}
This paper analyses the real economy effects of firms having some shareholders with a short investment horizon on their shareholder register. Short-term shareholders cause firms to be concerned with the path of the share price as well as its ultimate value. Such shareholders in an economy lead to bubbles in the prices of key inputs, to the misallocation of firms to risky business models, and to increased costs of capital. For individual firms short-term shareholders induce the Board to reduce deferred incentives in CEO pay prompting CEO myopia and reduced investments in the long-run capabilities of the firm.
\end{abstract}

Keywords: investor time-horizons; bubbles; short-termism; deferred pay; incentives; bonuses; shareholder register; corporate governance.

JEL Classification: G12, G34, L21, L25. 
"As long as the music is playing, you've got to get up and dance. We're still dancing." Chuck Prince, former Chairman and CEO of Citigroup, July 2007.

\section{Introduction}

The Board of a firm must account for its actions to the firm's shareholders. Shareholders are not homogeneous: they differ in their investment horizons and in their robustness to liquidity shocks. Short-termism amongst investors and shareholders has long been a concern amongst policy makers, academics and business leaders. This study uses theoretical Finance and Industrial Organization techniques to analyse the implications on the real economy of firms having some shareholders with a short investment horizon on their shareholder register.

This paper demonstrates that short-term shareholders can lead to bubbles in the prices of key inputs, to the misallocation of firms to risky business models, and to increased costs of capital. Short-term shareholders can induce the Board to reduce the level of deferred incentives in CEO pay prompting CEO myopia and reduced enhancements in the long-run capabilities of the firm. Finally the analysis demonstrates that short-term shareholders are caught in a prisoner's dilemma: once they hold a stock they would in private vote for the Board to be concerned with the share price path rather than long run value.

To explore the relationship between short-term shareholders and the real economy we first build a tractable general equilibrium model in which firm business choices, resultant input purchases, and shareholders interact. To analyse the implications for CEO pay and shareholder voting we then augment our analysis by a partial equilibrium analysis of the pressures on an individual firm. The driving assumption of this work is that the Board of a firm seeks to maximise the aggregate value of the shareholders on their register at the time a business decision is taken. This is one of two standard paradigms used in the Finance literature. For example, the Pecking Order theory of capital structure uses this assumption. Specifically, the seminal work of Myers and Majluf (1984) has the firm maximising the value of the old shareholders as opposed to those who might buy the stock in the future, and this distinction gives rise to the negative signalling effects of issuing equity. The second paradigm is to posit that firms maximise long run value. With the presence of shareholders this approach of npv value maximisation is delivered by the Fisher Separation Theorem (Fisher (1930, p141)). The Separation Theorem notes that value maximisation maximises every owner's consumption opportunity set and so would be unanimously supported. In capital markets in which risk-sharing opportunities are not complete, or asymmetric information exists, the application of the Fisher Separation Theorem is disputed (DeAngelo (1981)).

In the model studied the firms in an industry must decide between two competing 
business models. One business model offers a safe payoff, the second a risky one. Firms are not identical, they differ in their ability to harness the risky technology. For some firms the expected return from the risky technology will outweigh the expected return from the safe technology. The firm management, its Board, has better information as to its ability than investors. These assumptions have broad applicability. For example, prior to the financial crisis a bank could decide to pursue a business model of securitising Mortgage Backed Securities, or not. Banks would differ in their likely skill in identifying when to enter and when to exit this market, and which assets to securitise.

If the firms were held solely by long-term investors, each firm's Board could maximise its value by pursuing the business model with the greatest expected long run payoff. However, now suppose there are a proportion of short-term shareholders in the investing population. These are shareholders who will sell their stake before payoffs are fully realised. They may sell because their investment time-horizon is short, or because they suffer liquidity shocks. In either case such shareholders care about the price of the shares at the point they sell. The Board, representing the totality of the shareholder base, is therefore concerned for both the time-path of the share price as well as the final expected payoff.

An implication of asymmetric information is that the firm's choice of business model sends a signal to the market. Firms with higher expected values will pursue the risky project. As a result the choice of the risky business model leads to an increase in the short run value as the market infers that the firm type must be drawn from a set which includes high ability firms. Firms in an economy containing short-term shareholders will be willing to sacrifice some long run expected payoff for this short run price increase. This increases the demand amongst firms to develop the risky technology. In the words of the former CEO of Citigroup, the short-run shareholders encourage the firms to get up and dance.

To develop a business model the firm requires inputs. The presence of short-term shareholders increases the demand for the inputs required for the risky technology above the level justified by fundamentals. This pushes the price of the inputs required for the risky technology up. A bubble is created.

Further, as firms contend with more expensive inputs the scale with which they can enter the risky technology is reduced. Hence market clearing for the input implies more firms pursue the risky technology. Thus short-term shareholders in an economy leads to both prices for the inputs above the level justified by fundamentals, and to a misallocation of too many firms into the risky technology. It follows that an economy with short-term shareholders has firms which have reduced expected value and so whose cost of capital is higher than it would be with solely long-term investors.

Analysing in more detail, the type of a firm is not purely exogenous, it can be improved by virtue of the CEO and management team's efforts. In expanding the role in this 
analysis that the CEO plays in the relationship between shareholders and firm, it is also important to acknowledge that the chief executive officer will finally have to decide on the firm's direction - whilst carrying his or her Board. I therefore expand the analysis to have the Board setting a private incentive contract for the risk averse CEO. The CEO can improve the type of the firm and so enhance its prospects from the risky technology. But this comes at an effort cost leading to a moral hazard problem. As the decision to pursue the risky technology raises the short-run share price, the CEO can be induced to select the risky business line by offering sufficient reward on the short-run price. However this share price will not be impacted by efforts the CEO makes to raise future performance as the payoffs will not be realised in the short-term. The Board therefore faces a dilemma. They can motivate the CEO to give sufficient weight to the need to keep the short run share price up by using short-term remuneration. But this weakens the incentive to develop the long run capacity of the firm. Long run incentives could fix this problem, but they expose the CEO to risk and so are expensive, weakening the incentive to develop the risky technology at all.

Growth in the proportion of short-term shareholders on the register exacerbates this dilemma and leads to reduced long term incentives, increased CEO myopia, reduced effort for the long term, and too great an allocation of firms to the risky technology. With a large proportion of short-term shareholders on the register the Board is very worried about the short-term share price. They therefore wish to incentivise the CEO to pursue the risky technology for a wide range of firm types. It is cheaper to do this by lowering the deferred incentive and substituting short-run incentive. The deferred incentive is more risky, so is discounted by the CEO, and the benefit in terms of payoff will not accrue to the short-term shareholders. The market infer this and so the uplift in the short-run share price is modest. As a result it becomes expensive to motivate the CEO to select the risky technology at all and so the benefit to saving money by focusing on short-run incentives is reinforced.

We conclude the analysis by endogenising the Board's objective function and analysing a shareholder voting game. Shareholders are allowed to vote, in private, for whether the Board pursues short-run share price maximisation or longer term value maximisation. The privacy of the vote captures that in reality no shareholder can prove the absence of any communication between themselves and a member, or members, of the Board of a firm they own. Short-term shareholders suffer from a prisoner's dilemma. Ex ante the value of a firm would be maximised by asking the Board to pursue long run value maximisation. However, once a firm is owned the short-term shareholders would rather that the firm take actions which pool it with high value firms, irrespective of the long term outcome. Hence short-term shareholders are induced to vote for short-run value maximisation, while longer-term shareholders vote for the long term. Hence the objective function postulated for the Board is endogenised. 
The Literature Review follows in Section 2. The model is developed in Section 3 and the main results on bubbles, misallocation and cost of capital delivered in Section 4. Section 5 expands the CEO role and demonstrates CEO myopia. Section 6 endogenises the Board's objective function. The conclusion follows in Section 7 and all proofs are contained in Appendix A.

\section{Relationship To The Literature}

The claim that short-termism is a substantial problem for Anglo-Saxon economies is widely voiced by commentators and policy makers, ${ }^{1}$ and so an empirical literature has sought to assess how substantial a problem this might be for corporate behaviour. Asker, Farre-Mensa, and Ljungqvist (2010) is a recent contribution which compares investment behaviour amongst listed firms to matched unlisted ones. The authors provide evidence that the listed firms are less responsive to investment opportunities and smooth their earnings, arguing that this is evidence of short-termism. An alternative approach with complementary results is pursued by Derrien, Kecskes, and Thesmar (2013) who measure the frequency with which investors turnover their portfolios to proxy for their investment horizons. They demonstrate that if the investment horizon of a firm's owners is reduced, an undervalued firm will reduce the level of its investment and increase payouts to shareholders. Other empirical studies also provide evidence that short-term shareholders can adversely impact corporate performance. Polk and Sapienza (2009) demonstrate that firms held by shareholders with shorter investment horizons are less sensitive to investment opportunities. Bushee (1998) provides evidence that if a firm has short-term shareholders then it tends to reduce R\&D expenditures. Gaspar, Massa, and Matos (2005), and Chen, Harford, and Li (2007) provide evidence that firms who have investors with short investment horizons appear to do less well in acquisition situations. Graham, Harvey, and Rajgopal (2005), offer survey evidence in which managers claim to being willing to sacrifice long run profitable projects to meet short run earnings targets.

This rich empirical body of work connecting investor horizons and corporate behaviour has grown with a body of theoretical literature exploring what the effects of executive short-termism might be. ${ }^{2}$ In general the literature has assumed that executives' utility is a function of the firm's long term value and the current share price. Stein (1989) explores ex ante symmetric information between executives and the market, and an unobserved CEO level of investment decision. In this case the CEO is in a prisoner's dilemma. The CEO under-invests to boost the current stock price and so hope to convince the market that the firm is better than it is. This behaviour is anticipated by the market and so ultimately

\footnotetext{
${ }^{1}$ See, for example, the Aspen Institute (2009, p3), "it [short-termism] is system-wide, with contributions by and interdependency among corporate managers, boards, investment advisers, providers of capital, and government."

${ }^{2}$ See Stein (2003) for a broader survey of agency problems and corporate investment.
} 
there is no share price gain. Stein (1996) suggests that in this case improvements in corporate performance would be available from altering the manner in which investment hurdle rates were calculated. Stein (1989) is a model of managers forgoing investments which are unobservable to shareholders. Thus this is a signal jamming model. Bebchuk and Stole (1993) instead offer a model in which the firm chooses an investment level which is observable to the market. Hence the CEO is able to build a reputation for the firm. In this setting the CEO who is exogenously concerned with the short-term share price will over invest. Miller and Rock (1985) make the same point in a model in which dividends are used to signal. As in Bebchuk and Stole (1993) and Miller and Rock (1985) mine is a model of signalling, not of signal jamming. Relative to this body of work I embed CEO myopia in a general equilibrium framework and so derive implications for the assignment of firms in an economy with short-termism to risky/safe business models; I derive implications for the asset prices of required inputs and document the rationale for bubbles; and I endogenise the CEO's utility by modelling the relationship between the composition of the shareholder register, the CEO incentive contract with both deferred and immediate incentives, and the corresponding business outcomes.

Investor planning horizons and adverse corporate outcomes have been explored in some other studies. Shleifer and Vishny (1990) suggest that long term investments can be mispriced for longer. Therefore assuming that executives are more sensitive to a drop in the short-run share price, than to an increase in its level, the authors argue that long run investments will be avoided. Goldmand and Strobl (2011) argue that the manager can inflate the share price by investing in complex assets whose payoff times differ from those of large institutional blockholder who could acquire information. The blockholders can be induced to signal that their information is positive by buying stock, so raising the share price and so executives' pay. The study I offer here endogenises the CEO utility function, and provides an analysis of economy wide outcomes on prices and firm allocations to business models, all of which are extensions to this literature.

The study here, and those documented above, are of rational short-termism: investors and managers have common priors and are expected utility maximisers. Short-termism amongst managers can also be explained when investors have behavioural features, such as differing priors as to a firm's prospects. Bolton, Scheinkman and Xiong (2006) derive the optimal remuneration structure when the owners of a firm calculate that they can sell to over-optimistic outside investors. The CEO can be encouraged to select projects which will be misvalued by buyers by rewarding the CEO sufficiently in terms of shortterm results. Like Bolton et al. (2006) this study calculates optimal CEO remuneration. However unlike Bolton et al. the study here is one of rational investors and signalling, thus the mechanism analysed is entirely different. Further, the study offered here embeds the analysis in a general equilibrium framework allowing results on the assignment of firms to business models, and on bubbles in the price of inputs to be derived. 
There is a rich literature on bubbles in asset markets, but to my knowledge this is the first study which links shareholders with corporate behaviour and hence with bubbles. ${ }^{3}$ The analytical approach pursued here draws on the insights of Allen and Gale (2000). Allen and Gale (2000) offer a model of asset bubbles in which investors borrow from a banking sector which cannot observe their investments. Due to assumed limited liability the investors seek to risk shift and move the funds into the risky asset, thus pushing the price of the risky asset above fundamental levels. Using a similar mechanism Allen and Gorton (1993) have both skilled and unskilled portfolio managers. The unskilled managers seek to profit from their limited liability and so are willing to buy assets at a price which is above fundamentals. This gives rise to investors with differing time horizons, as well as bubble phenomena. Unlike these works, there is no risk-shifting rationale in the framework here. Rather maximisation of shareholder value is linked to firms' business allocation decisions. Further this prior work on bubbles is silent on the optimal incentive contracts for the CEOs of firm's subject to the modelled effects on their share price.

Finally the work here contributes to the literature on the optimal time profile for executive compensation to manage myopia. Bolton, Scheinkman and Xiong (2006) has been discussed above. Thanassoulis (forthcoming) links optimal CEO incentives with industry structure. Thanassoulis (forthcoming) argues that in concentrated industries some firms will endogenously decide to offer contracts which overweight short-term results relative to long term performance as the costs of dealing with the effort problem rise more slowly than the costs of dealing with myopia as the executives' outside option rises. He (2012) numerically derives the optimal contract if an executive can save and take myopic actions. Edmans et al. (2012) explicitly derive the optimal incentive contract in this setting whereby the executive can save and take myopic actions. All of these models endogenise the CEO contract and demonstrate that deferral of pay is part of the optimal contract. Unlike these prior works, here I link the optimal CEO incentive contract to the composition of the shareholder register. Further, by embedding the study in a general equilibrium context the implications for bubbles and firm allocations to different technologies are derived and are entirely new.

\section{The Model}

Consider a continuum of firms indexed by type variable: $\tau \in[0,1]$. The types of firms in the population are distributed according to the cumulative distribution function $G(\tau)$ with probability density $g(\tau)$. The Board of the firm knows its type and selects a business activity at time $t=1$. There are two possible business activities to select from. The Board can choose to develop a safe technology. This technology requires an input priced at the numeraire of 1 and yields a certain payoff at $t=2$ of $r>1$. Alternatively the Board can

\footnotetext{
${ }^{3}$ For a review of the broader literature on bubbles see Camerer (1989).
} 
choose to develop a risky technology. In this case the firm must buy a different input labelled the productive asset. It has a price per unit of $P$. The $t=2$ payoff from a unit of the risky technology is random and distributed according to $h_{\tau}(\cdot)$. The distribution of payoffs is indexed by the firm type, $\tau$, which captures the ability of the firm in this activity. Higher $\tau$ firms have a payoff from developing the risky technology which first order stochastically dominates the payoff from a less able, lower $\tau$, firm. Hence if $\tau_{1}>\tau_{2}$ then $E\left(h_{\tau_{1}}\right)>E\left(h_{\tau_{2}}\right)$. Setting $\bar{R}:=E\left(h_{\tau} \mid \tau=1\right)$ to be the expected payoff of the most talented firm, by relabelling the index $\tau$, we can without loss of generality set the expected payoff from developing the risky technology of a firm of type $\tau$ to be: ${ }^{4}$

$$
\Pi^{\text {risk }}(\tau)=\bar{R} \tau
$$

The price, $P$, of the productive asset will be determined in equilibrium. Each firm is assumed to have a unit of capital. Further, the productive asset is assumed to be in restricted supply of $b<1$. It is therefore not possible for every firm to develop the risky technology. We assume that

$$
\bar{R}>r>\bar{R} b
$$

Which guarantees that we remain within an interior solution and so that an intermediate proportion of firms will develop the risky technology.

This is a model which captures a firm's decision as to whether or not to enter a potentially risky business line. For example, the productive asset may be sub-prime mortgages which can be used to create profits via securitisation; or alternatively the productive asset may be property which a firm can seek to profit off by developing for sale. The productive asset captures the specific input needed to access the risky business line.

The equity of the firms is owned by shareholders of which there are two types. Some shareholders are long term buy-and-hold investors. They will hold their shares until the payoffs are realised at $t=2$. The remaining shareholders are short-term shareholders. They will not hold their shares until the payoffs are realised. The short-term shareholders will sell their shares at the end of $t=1$, after the Board make their business line decision, but before the profits are realised. Thus we combine the repeated short-life shareholders of, for example, Bhattacharya (1979) with buy and hold investors. The short-term shareholders can be motivated as investors who have liquidity needs, or as investors with short time horizons. I assume that the Board knows the proportion of short-term shareholders on its register. Bushee (1998) offers academic evidence that this is so. In reality the composition of the shareholder register is monitored careful by the Chairman. For example the Chairman of Cadbury, the main UK confectionery company until its purchase by

\footnotetext{
${ }^{4}$ This is without loss of generality as variation in the payoffs can be captured through the distribution of firms, $g(\tau)$.
} 
Kraft, commented in interview that "the seeds of destruction of this company lay in its [shareholder] register." 5

We suppose that all firms in the industry have the same proportion $L \in[0,1)$ of shortterm shareholders. The objective function of the Board is to seek to maximise the value generated for the shareholders on the register at the time the business decision is made.

The timeline of the entire model is depicted graphically in Figure 1. I restrict attention in the analysis to pure strategy equilibria.

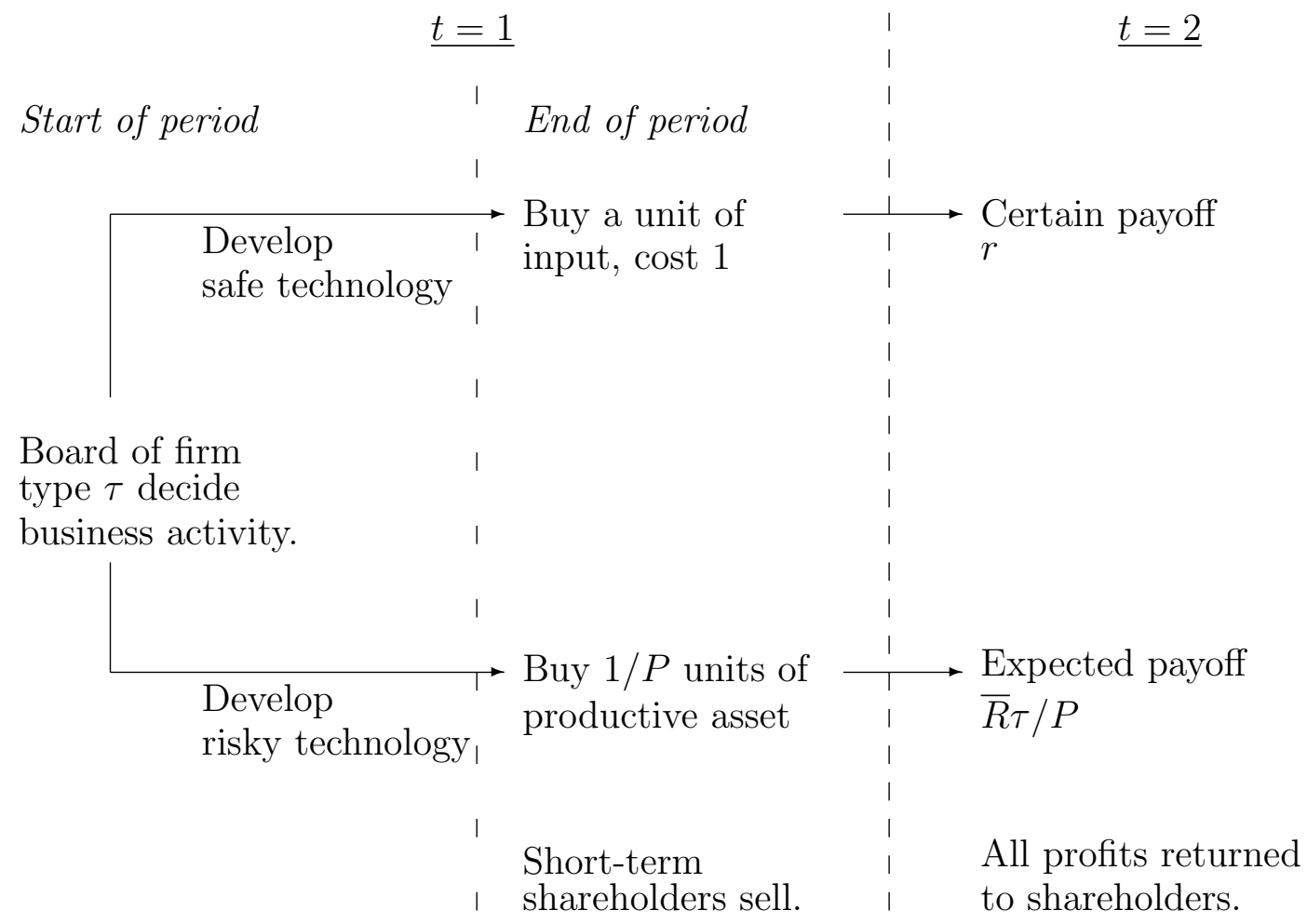

Figure 1: Time line of the model.

Notes: The Board select the business line of the firm so as to maximise the value of the shareholders on the register at the point the decision is made. Short-term shareholders sell after the business decision, but before payoffs are realised. Long term sharholders will hold their shares until the payoffs are realised. Firms are enowed with a unit of capital which they use to buy the required input for the business chosen. Payoffs from the risky technology are uncertain. All payoffs are returned to shareholders at the end of $t=2$.

\footnotetext{
${ }^{5}$ See Financial Times, March 12, 2010, 'The inside story of the Cadbury Takeover.'
} 


\section{Analysis of Shareholder Effects}

In this section we solve the model to explore the relationship between short-term shareholders, the price of the input to the risky technology, and the allocation of firms to business lines.

\subsection{Productive Asset Fundamental Value}

The fundamental value of the productive asset can be found by calculating the equilibrium price when all the buyers of the asset are long-term value maximisers (Allen and Gale (2007)). This is the natural analogue of the definition of fundamental value offered by Allen, Morris, and Postlewaite (1993) that every agent holding or buying the asset should be willing to do so if they were forced to maintain their holdings for ever.

If a firm of type $\tau$ invests in the safe technology then it generates a payoff of $r$. If instead it invests in the risky technology then it invests at a scale of $1 / P$ and so its expected payoff is $\bar{R} \tau / P$.

It is immediate that if a firm of type $\tau$ would invest in the risky technology, so would all firms of higher type. Market clearing at the fundamental price $P^{f}$ requires that the total supply of the productive asset is bought. Define the function $q(y)$ as the type for which there exists a mass $y$ of more talented firms. Thus $G[q(y)]:=1-y$. The market clearing condition is then that firms $\tau \in[\hat{\tau}, 1]$ invest in the risky technology where

$$
\int_{\tau=\hat{\tau}}^{1} \frac{1}{P^{f}} g(\tau) d \tau=b \Rightarrow \hat{\tau}=q\left(b P^{f}\right)
$$

Market clearing requires the borderline firm $\hat{\tau}$ to be indifferent between developing the risky and the safe technology. Hence the fundamental price $P^{f}$ is defined implicitly by the relation

$$
\bar{R} q\left(b P^{f}\right) / P^{f}=r
$$

We can demonstrate that:

Lemma 1 There exists a unique fundamental price for the productive asset. The fundamental price satisfies $0<P^{f}<1 / b$.

\subsection{Bubbles and Misallocation}

We now analyse the general model in which firms have a proportion $L$ of short-term shareholders on their shareholder register. A strategy for the Board of each firm is a decision function which maps the proportion of short-term shareholders on the register to a choice between developing the risky technology or the safe technology. Thus a strategy is equivalent to a partition of the firm type space into $T^{\text {safe }}$ and $T^{\text {risk }}$ such that 
$T^{\text {safe }} \cup T^{\text {risk }}=[0,1], T^{\text {safe }} \cap T^{\text {risk }}=\varnothing$ and if $\tau \in T^{\text {risk }}$ then the Board decides to develop the risky technology, and not otherwise. It follows that, observing the business model chosen, the market can make inferences as to the set of types which the firm must be drawn from. This will affect the price short-term shareholders will receive when they sell.

Lemma 2 If a firm of type $\tau$ with a proportion $L$ of short-term shareholders should develop the risky technology then the Board's objective function at $t=1$ takes value $V^{\text {risk }}(\tau, L)$ given by:

$$
V^{\text {risk }}(\tau, L)=(1-L) \cdot \underbrace{\Pi^{\text {risk }}(\tau)}_{\text {Expected payoff }}+L \cdot \underbrace{E\left(\Pi^{\text {risk }}(\tau) \mid \tau \in T^{\text {risk }}\right)}_{\text {Share price at end } t=1}
$$

The Board seeks to maximise the aggregate value of the shareholders. The $1-L$ longterm shareholders will see the realised payoffs. The expectation of this payoff is $\Pi^{\text {risk }}(\tau)$. The $L$ short-term shareholders will sell their holding before the business results are realised. Thus what matters to these shareholders is the market price they receive for their stock. This market price is determined by the market's expectation of the payoffs which will be realised. The share price at point of sale will be the expectation $E\left(\Pi^{\text {risk }}(\tau) \mid \tau \in T^{\text {risk }}\right)$. This expectation depends upon the inferences the market makes from the Board's choice of business model.

Lemma 2 demonstrates that an immediate implication of the assumption that the Board maximise the value of the shareholders on the register at the point of taking a business decision is that the Board's objective function is a weighted average over the path of share prices as well as the expected net present value of the business decision. The weights in the objective function depend upon the proportion of short-term shareholders on the register: $L$.

To make progress as to the Board's decision it is necessary to understand the market's inference problem. This in turn depends upon the equilibrium strategy of the Board.

Lemma 3 In any pure-strategy equilibrium of this model, the Board's strategy takes a cut-off form: if firm type is above some level $\tau^{*}$ then the Board decides to develop the risky technology; otherwise it develops the safe technology.

The proof follows by showing that firms of higher type $\tau$ create greater expected value for their long-term shareholders from the risky technology than firms with lower type. While it can be shown that short-term shareholders are indifferent between all firms which select the same technology. The partition of the type space then follows.

As firms are in part concerned with the path of their share price, the Board perceive a signalling value and/or cost in the choice of business model. If the Board choose to develop the risky technology then they will allow the short-run share price to rise. However the 
business requires inputs, and as firms seek to buy the input they will force the price of it up. This brings us to the first main results of this analysis:

Proposition 4 Suppose that all firms have a proportion $L>0$ of short-term shareholders on their shareholder register. The productive asset price satisfies:

$$
r=\frac{\bar{R}}{P} q(b P)+L \frac{\bar{R}}{b P^{2}} \int_{\tau=q(b P)}^{1} 1-G(\tau) d \tau
$$

This implies:

1. Short-term shareholders create a bubble in the price of the productive asset: $P \supsetneqq P^{f}$.

\section{Inefficiently many firms develop the risky technology.}

To understand the result suppose that there was no bubble and the price of the productive asset were at its fundamental level of $P^{f}$ as given in equation (4). Each firm which pursues the risky technology will do so at a scale of $1 / P^{f}$. As the supply of the productive asset is fixed at a total volume of $b$, the marginal firm which invests in the risky technology will have type $\tau=q\left(b P^{f}\right)$ so that the total mass $b$ of productive asset is bought. Now consider the incentives for the Board of a firm of type just below this level, say type $\tau=q\left(b P^{f}\right)-\varepsilon$ for $\varepsilon$ arbitrarily small yet positive. At the fundamental price $P^{f}$ for the productive asset the net present value of the risky technology is below that from the safe technology. Thus long term-shareholders would lose out slightly from a decision to invest in the risky technology. The net present value would fall by an amount proportional to $\varepsilon$. However, if the Board of the firm of type $q\left(b P^{f}\right)-\varepsilon$ did invest in the risky technology then the market would infer, mistakenly, that the firm was drawn from type $\tau \in\left[q\left(b P^{f}\right), 1\right]$. Hence the market price at the end of $t=1$ would jump up. This would represent a gain for the short-term shareholders of constant order and so would outweigh the loss to the long-term shareholders.

This implies that firms of type below $q\left(b P^{f}\right)$ would buy the productive asset at its fundamental price. However the supply of the fundamental asset is not perfectly elastic. This extra demand at the fundamental price will force the price of the productive asset up. Hence a bubble is created in the productive asset.

All the firms which invest in the risky technology now face a higher price for the productive asset, and so they use less of it and enter the risky technology at a smaller scale. Market clearing for the risky asset then requires that more firms decide to invest in the risky technology. Thus the proportion of firms which seek the risky technology grows as compared to the efficient level with no short-term shareholders. 


\subsection{Comparative Statics}

As the proportion of short-term shareholders in the economy increases, the incentives for firms to pursue the risky technology against the interest of long-run value maximisation grow.

Proposition 5 If the proportion of short-term shareholders in the economy should increase:

1. The bubble in the price of the productive asset increases.

2. The proportion of firms selecting the risky technology rises.

3. The average payoff of firms which develop the risky technology falls.

Proposition 5 demonstrates that the impact of short-term shareholders on the economy's outcomes is monotonic. If the proportion of short-term shareholders increases, then the greater the reduction in long-run value a Board is willing to accept in return for the increase in the value received by the short-run shareholders. This increases the willingness of firms to invest in the productive asset and develop the risky technology. This increase in demand for the productive asset forces its price up. It also exacerbates the misallocation of firms to technologies as firms are able to buy less of the more expensive productive asset, and so market clearing requires more firms to switch to the productive asset. The average payoff of a firm conditional on its developing the risky technology falls as more low type firms join this group.

We conclude this analysis by noting that short-term shareholders also affect the firms' implied cost of capital. Suppose that the firms had to raise their unit of capital from the equity markets prior to the start of the game. At this point investors would be unaware of the firm's type. A firm valued in expectation at $V$ would have to sell a shareholding of $1 / V$ to secure a unit of equity capital. The larger is the valuation, $V$, the smaller is the cost of capital. The equity market is composed of both long term buy-and-hold investors, and short-term shareholders. We will see that these shareholders both agree on the value of a representative firm prior to $t=1$ allowing us to demonstrate that:

Proposition 6 The firms' cost of capital grows with the proportion of short-term shareholders in the population.

With numerous short-term shareholders a larger set of firm types would wish to develop the risky technology to raise its interim share price, even at a cost to long-term shareholders. Hence there is a greater probability that the firm will choose a business line not its long term interests. This is a misallocation effect which lowers the expected payoff of those firms who should have opted for the safe technology, but instead will opt for the risky technology. Further, there is also a second general equilibrium effect. An increase 
in the proportion of short-term shareholders raises the price of the productive asset, and this lowers the expected value of any firm developing the risky technology. Hence through this channel also the representative firm sees its value decline. Both of these effects raise the cost of capital of a representative firm as the expected firm value declines.

\section{CEO Incentive Pay}

I now extend the model to provide a meaningful role for the CEO. I consider a single firm within the market and suppose the CEO has the ability to improve the firm's type, at some personal effort cost. Hence the Board face a moral hazard problem. Secondly, I allow the CEO to ultimately decide which business model should be pursued. In reality the choice of business model is a matter for agreement between the Board and the CEO. However it is in practice impossible to proceed without the CEO's consent, without also removing the CEO. Thus the polar case of the CEO deciding is a relevant one to consider.

Any improvements made by the CEO to the firm type will not be observable until payoffs are realised. Hence to incentivise the CEO to undertake such improvements, pay must include a sufficient delayed and so risky component. A risk averse CEO will discount such pay, and so it is expensive for the Board to reward in this way. It is not however possible for the Board to avoid delayed remuneration as rewarding solely on early returns negates the benefit of improving the firm's ability levels, whilst it does affect the choice of business line. This insight suggests that short-term shareholders will incentivise CEOs too heavily with short-term rewards which encourage the excessive development of the risky technology by lower ability firms. However the market can observe the shareholder register and so will make accurate inferences. This section analyses this situation in a partial (as opposed to general) equilibrium framework to determine the equilibrium impact of short-term shareholders via possible CEO myopia.

\subsection{Extending The Model To Include The CEO}

Suppose that the firm type, $\tau$, is known to the Board and is observed by the CEO prior to contracting at an earlier $t=0$. To avoid corner solutions allow the firm type $\tau$ to be distributed on the positive reals so the support of the distribution function $G(\cdot)$ is $\mathbb{R}_{+}$. As in the above model, the market do not directly observe the firm type. To study CEO contracting I use the standard approach of normal payoffs and CEO mean-variance utility as used by Bolton, Scheinkman and Xiong (2006) for example. Such a formulation can be justified, for example, if the CEOs utility function were exponential and of constant absolute risk aversion. ${ }^{6}$ More broadly such an approach is a tractable way of modelling a risk averse agent. If the CEO's financial stake in the firm is $W$ then the expected utility,

\footnotetext{
${ }^{6}$ See, for example, Varian (1992, s.11.7).
} 
gross of the effort cost is:

$$
E(U(W))=E(W)-(\rho / 2) \operatorname{var}(W)
$$

The parameter $\rho$ is the CEO's coefficient of absolute risk aversion.

Once hired, the CEO decides, as above, at the start of $t=1$ between implementing the safe or the risky technology. If the CEO decides to implement the risky technology then he can raise the type of the firm by an amount $\eta$ to type $T=\eta+\tau$. This comes at a personal effort cost of $\kappa \eta^{2} / 2$. Such a quadratic assumption is convenient due to its tractability. It is not an essential assumption. In the case of developing the risky technology, the payoff at $t=2$ per unit of productive asset is assumed to be distributed according to the normal distribution $X_{2}(T) \sim N\left(\bar{R} T, \sigma^{2}\right)$ with mean $\bar{R} T$ and variance $\sigma^{2}$. This is a restriction on the benchmark model which allowed for any distribution of payoffs. The assumption is made so that the certainty equivalent of the CEO's utility takes the simple form of mean less variance, as given in (7). The variance of the payoff is unrelated to the firm type, so higher type firms have their distribution of payoffs purely shifted to the right. If instead the CEO develops the safe technology then the payoff is known with certainty as $r$.

To participate at $t=0$ the CEO must receive expected utility at least as great as his outside option, denoted $u$. The effort component, $\eta$, is chosen by the CEO after contracting. I normalise the discounting of the CEO and the firm to 0. The Board can remunerate the CEO through a fixed wage payment $f$, a bonus $b$ as a proportion of market value at $t=1$, or a deferred (or vested) bonus at $t=2$ as a proportion $v$ of realised value, or any combination. The bonus elements agreed between the Board and the $\mathrm{CEO}$ at $t=0$ are private information to the contracting parties. This assumption captures that in reality the Board is not bound by indicative bonus rates it puts in the public domain. One case study example is provided by the CEO of BP in 2010. The share price performance over the period 07-09 would have led to no share award according to the publicly published criteria. In the event the CEO was awarded a bonus of shares equal to over $80 \%$ of base pay. ${ }^{7}$

The market value of the firm at time $t=1$ is denoted $X_{1}$. If the firm develops the risky technology then this market value will depend upon market beliefs as to the prevailing CEO contract. Thus the CEO receives the following remuneration:

$$
W=f+b X_{1}+v X_{2}
$$

\subsection{Long term Shareholders Only Benchmark}

In the absence of any short-term shareholders, the Board are purely motivated to maximise the net present of the firm. As we are considering an individual firm we ignore general

\footnotetext{
7 "BP's Hayward Given 41\% Increase," Financial Times, March 5, 2010.
} 
equilibrium effects and assume that the price of the productive asset is fixed at $P$.

By reasoning analogous to Lemma 3 if the CEO develops the risky technology then the market believe the firm is distributed on $[\tilde{T}, \infty)$ according to some distribution $\Gamma(T)$. This distribution will depend upon the CEO actions, and in equilibrium the market's beliefs must be correct. If the CEO chooses risky then the firm will be valued at $t=1$ by $X_{1}=\int_{T=\tilde{T}}^{\infty}(\bar{R} / P) T d \Gamma(T)$. The Board can, in private, alter the incentives offered to the $\mathrm{CEO}$ and select the remuneration contract with parameters $\{f, b, v\}$. If the CEO chooses the risky technology then the payment to the CEO will be $W^{\text {risk }}(\tau)=f+b X_{1}+v X_{2}(\eta, \tau)$. The market will not know of any change to the remuneration contract and so will not price in the changes to the share price. The utility of the CEO from the risky choice is denoted $U^{\text {risk }}(\tau)$ and is given, using the mean-variance assumption, by

$$
U^{\text {risk }}(\eta, \tau)=f+b \int_{T=\tilde{T}}^{\infty} \frac{\bar{R}}{P} T d \Gamma(T)+v \frac{\bar{R}(\eta+\tau)}{P}-\frac{\kappa}{2} \eta^{2}-\frac{\rho}{2} v^{2} \sigma^{2}
$$

Lemma 7 If the CEO decides to invest in the risky technology, he will improve the firm type by an amount $\eta^{*}$ :

$$
\eta^{*}=\frac{v}{\kappa} \frac{\bar{R}}{P}
$$

Proof. Direct optimisation of CEO utility, (8), with respect to the effort level $\eta$.

Lemma 7 demonstrates that the CEO's effort choice only depends upon the deferred bonus. Before the realisation of results, private effort exerted to raise the expected payoffs of the business cannot be verified by the market, and so is not reflected in the early share price. Early bonuses are not without purpose however, they can be used to incentivise the choice of business the CEO will pursue. In this case this is a choice between the safe and the risky technology.

Lemma 8 The CEO will prefer the risky to the safe technology if:

$$
b \underbrace{\left[\int_{T=\tilde{T}}^{\infty} \frac{\bar{R}}{P} T d \Gamma(T)-r\right]}_{(i)} \geq v \underbrace{\left[r-\frac{\bar{R} \tau}{P}\right]}_{(i i)}-\frac{1}{2} \underbrace{\left[\left(\frac{\bar{R}}{P}\right)^{2} \frac{1}{\kappa}-\rho \sigma^{2}\right]}_{(i i i)} v^{2}
$$

And, if (10) is satisfied, will accept the contract if

$$
f+b \int_{T=\tilde{T}}^{\infty} \frac{\bar{R}}{P} T d \Gamma(T)+v \frac{\bar{R} \tau}{P}+\frac{1}{2}\left[\left(\frac{\bar{R}}{P}\right)^{2} \frac{1}{\kappa}-\rho \sigma^{2}\right] v^{2} \geq u
$$

Lemma 8 determines the restrictions on the contract the Board can offer which ensure that the CEO both accepts the contract, and then selects the risky technology. Equation (10) is the CEO's incentive compatibility constraint. It ensures that the CEO prefers implementing the risky technology to the safe technology. If the CEO implements the 
risky technology, then the share price of the firm will increase due to the signalling effect which pools the firm with high type firms. The bracket $(i)$ captures the extent of the price uplift as the share price conditional on selecting the risky technology is given by $X_{1}=\int_{T=\tilde{T}}^{\infty} \bar{R} T / P d \Gamma(T)$, whereas developing the safe technology would yield a payoff of $r$. The CEO internalises this jump in short-run value via his short-term bonus, $b$. If $b$ is made sufficiently large then the CEO is incentivised to select the risky technology. The bonus must be large enough to outweigh any reduction in the expected payoff from the risky technology, bracket $(i i)$, and also the increase in risk and the cost of effort from the risky technology less the increase in the $t=2$ expected payoff as a result of the effort, bracket $($ iii) .

Equation (11) is the participation constraint. It measures the CEO's utility from developing the risky technology, allowing for the result from Lemma 7 which determines the effort the $\mathrm{CEO}$ will exert. If the utility from the contract exceeds the outside option, then it is acceptable to the CEO.

Now we consider the Board's problem in this benchmark case in which there are no short-term shareholders. If the Board seeks to incentivise the risky technology when the firm type is $\tau$ then the Board's objective function is to choose the contract which maximises the expected payoff $\bar{R}\left(\eta^{*}+\tau\right) / P$ less the expected payment to the CEO, subject to the incentive compatibility and participation constraints, (10) and (11). The fixed fee $f$ is a direct transfer from the firm to the CEO, and so it is optimally reduced until the participation constraint is binding. ${ }^{8}$ Substituting in for the effort level selected by the CEO, $\eta^{*}$ as given in Lemma 7 , the Board's value from incentivising the risky technology is $V^{\text {risk }}(b, v)$ :

$$
\begin{aligned}
V^{\text {risk }}(b, v ; \tau)= & \frac{\bar{R}}{P} \tau+\left(\frac{\bar{R}}{P}\right)^{2} \frac{v}{\kappa}-\frac{1}{2}\left(\frac{\bar{R}}{P}\right)^{2} \frac{v^{2}}{\kappa}-\frac{\rho}{2} v^{2} \sigma^{2}-u \\
& \text { Subject to }(10)
\end{aligned}
$$

This allows us to characterise the optimal incentive contract for the CEO.

Proposition 9 The critical firm type is given by

$$
\tilde{\tau}=\frac{P}{\bar{R}}\left[r-\frac{\left(\frac{\bar{R}}{P}\right)^{2} \frac{1}{\kappa}}{2\left[1+\left(\frac{P}{\bar{R}}\right)^{2} \kappa \rho \sigma^{2}\right]}\right]
$$

1. If the firm type $\tau$ is greater than the critical firm type $\tilde{\tau}$ then the Board will incentivise

\footnotetext{
${ }^{8} \mathrm{I}$ allow for negative $f$ which captures settings in which the CEO must first make a payment to the firm in return for being hired with the incentive pay schedule.
} 
the CEO to develop the risky technology. They will offer a long term incentive bonus:

$$
v=1 /\left[1+\left(\frac{P}{\bar{R}}\right)^{2} \kappa \rho \sigma^{2}\right]
$$

which incentivises the CEO to increase the firm type by:

$$
\eta^{*}=\left(\frac{1}{\kappa} \frac{\bar{R}}{P}\right) /\left[1+\left(\frac{P}{\bar{R}}\right)^{2} \kappa \rho \sigma^{2}\right]
$$

A strictly positive short-term bonus $b$ is required if

$$
\tau<\underbrace{\frac{P}{\bar{R}}\left[r-\frac{\left(\frac{\bar{R}}{P}\right)^{2} \frac{1}{\kappa}}{2\left[1+\left(\frac{P}{\bar{R}}\right)^{2} \kappa \rho \sigma^{2}\right]}\right]}_{=\tilde{\tau}}+\frac{P}{\bar{R}} \frac{\rho \sigma^{2}}{2\left[1+\left(\frac{P}{\bar{R}}\right)^{2} \kappa \rho \sigma^{2}\right]}
$$

2. If the firm type $\tau$ is below the critical firm type $\tilde{\tau}$, then the Board will incentivise the CEO to develop the safe technology. They will not use incentive pay and set the fixed fee $f=u$.

All firms with type $\tau \in[\tilde{\tau}, \infty)$ will develop the risky technology. The distribution of firms which develop the risky technology is therefore supported on

$$
T \in\left[\tilde{\tau}+\eta^{*}, \infty\right)=\left[\frac{P}{\bar{R}} r+\frac{\frac{\bar{R}}{P} \frac{1}{\kappa}}{2\left[1+\left(\frac{P}{\bar{R}}\right)^{2} \kappa \rho \sigma^{2}\right]}, \infty\right)
$$

And the distribution function is given by

$$
\Gamma(T)=\frac{G\left(T-\eta^{*}\right)}{1-G(\tilde{\tau})}
$$

With $\tilde{\tau}$ given in (13), and the optimal improvement in firm type, $\eta^{*}$, given by (9).

Proposition 9 gives a characterisation of the optimal CEO incentive contract with market inference and no short-term shareholders. If the firm type is above a critical level, the Board will prefer to incentivise the CEO to pursue the risky technology. The CEO is incentivised to improve the firm by being exposed to some long term incentive pay. This pay will be valuable when payoffs are realised, and so creates an incentive to truthfully improve the firm type. If the type of the firm is sufficiently near the critical point at which it would be optimal to pursue the safe technology in preference to the risky project, then short-term bonus must also be used to create sufficient incentive for the CEO to be willing to accept the payoff risk of pursuing the risky technology. 
If instead the firm type is below the critical level $\tilde{\tau}$, then the Board are content for the CEO to develop the safe technology, and so high powered incentives are not required.

\subsection{Short-Term Shareholders}

We now analyse the impact short-term shareholders have on CEO incentives and so on equilibrium outcomes. The proportion $L$ of short-term shareholders on the firm's register is public information, and it will affect the distribution of firms $\Gamma(T)$ which the market believes a firm pursuing the risky technology is drawn from. However, by inspection of the logic above we see that Lemma 7 holds so that the CEO will select, if he opts for the risky technology, an improvement to the firm's type of $\eta^{*}$ given by (9). Further Lemma 8 also holds so that the CEO will select the risky technology at all, and so the contract will be incentive compatible, if (10) holds; and in this case the contract will be acceptable, so we will have the participation constraint satisfied, if (11) holds.

The Board however internalises the views of the all their shareholders. Hence the objective function from incentivising the risky technology changes to

$$
\begin{aligned}
& \max _{\{f, b, v\}} L \int_{T=\tilde{T}}^{\infty} \frac{\bar{R}}{P} T d \Gamma(T)+(1-L) \frac{\bar{R}}{P}\left(\eta^{*}+\tau\right)-\left\{f+b \int_{T=\tilde{T}}^{\infty} \frac{\bar{R}}{P} T d \Gamma(T)+v \frac{\bar{R}}{P}\left(\eta^{*}+\tau\right)\right\} \\
& \text { subject to (10) and (11). }
\end{aligned}
$$

The Board's problem can be solved to yield the following characterisation:

Proposition 10 Given a proportion $L$ of short-term shareholders on the register, the critical firm type is given implicitly by

$$
L \int_{\tau=\tilde{\tau}}^{\infty} \frac{\bar{R}}{P}\left(\tau+\eta^{*}\right) \frac{g(\tau)}{1-G(\tilde{\tau})} d \tau+(1-L) \frac{\bar{R}}{P} \tilde{\tau}+\frac{(1-L)^{2} \frac{1}{2}\left(\frac{\bar{R}}{P}\right)^{2} \frac{1}{\kappa}}{\left[1+\left(\frac{P}{\bar{R}}\right)^{2} \kappa \rho \sigma^{2}\right]}=r
$$

1. If the firm type $\tau$ is greater than the critical firm type $\tilde{\tau}$ then the Board will incentivise the CEO to develop the risky technology. They will offer a long term incentive bonus:

$$
v=(1-L) \frac{1}{\left[1+\left(\frac{P}{\bar{R}}\right)^{2} \kappa \rho \sigma^{2}\right]}
$$

which incentivises the CEO to increase the firm type by:

$$
\eta^{*}(L)=\frac{(1-L)}{\kappa} \frac{\bar{R}}{P} \frac{1}{\left[1+\left(\frac{P}{\bar{R}}\right)^{2} \kappa \rho \sigma^{2}\right]}
$$

2. If the firm type $\tau$ is below the critical firm type $\tilde{\tau}$, then the Board will incentivise 
the CEO to develop the safe technology. They will not use incentive pay and set the fixed fee $f=u$.

From comparison of the optimal deferred bonus as given in Proposition 10 to that given in the benchmark case of only long-term shareholders (Proposition 9), the CEO's remuneration has a lower deferred bonus and so the CEO is incentivised to improve the firm's type less when there are short-term shareholders on the register. The benefits of improving the firm type will only accrue to those holding shares at $t=2$ as the market does not observe and so the price cannot reflect the improved type prior to that date. Shortterm shareholders will not benefit, and so do not want to pay for the incentives. Further we see below that short-term shareholders continue to exacerbate the misallocation effect even when the business decision is delegated to the CEO. Even though short-term shareholders do not wish to improve the firm's type, conditional on developing the risky technology, they do want to incentivise the risky technology to be chosen. Hence pay is increasingly weighted to short-term bonus. As the proportion of short-term shareholders rises, the Board will prefer to incentivise increasingly weak firms to take the risky technology.

Proposition 11 As the proportion L of short-term shareholders on the register increases, then the Board:

1. Incentivise the risky technology for inefficiently too many firm types;

2. They incentivise the CEO to improve the firm less;

3. They reduce the weighting on deferred bonus.

The firm seeks the risky technology more frequently with increasing $L$. Hence the value of selecting the risky technology as a signal for an enhanced $t=1$ valuation, falls. Further the Board incentivise a lower level of firm improvement. Hence for this reason also the firm value declines. It follows as a corollary that the firm's cost of capital rises.

Corollary 12 The ex ante firm value declines in the proportion of short-term shareholders, and the cost of capital increases.

The Board are in a form of prisoners' dilemma. If the proportion of short-term shareholders on the register should grow, the market will expect the Board to incentivise less deferred bonus $(v)$ as they are not interested in investments which only move the share price in the long term. In addition the market expects the shareholders to be served by over-weighting the short run bonus (b) so as to encourage the risky technology to be developed. The market therefore discount the risky technology as a signal of quality. Hence the benefit to the share price of incentivising risks is reduced. But with more short-term shareholders, it is still desirable, validating the market's inference. 


\section{Endogenising The Board's Objective Function}

We have analysed the implication of the Board's objective function being to maximise the value of the shareholders on its register at the time that the business decision is taken. As short-term shareholders will sell before the final results are realised, the path of the share price becomes part of the Board's concerns. However, all shareholders, both long-term and short-term, value a company less the more the share-price path is emphasized to the detriment of long run value. Therefore this section endogenises the Board's objective function.

\subsection{A Model of Shareholder Voting}

We return to our benchmark model of Section 3 in which the Board make the business decision, and firm types are distributed according to $g(\tau)$ on $[0,1]$. We extend the model back to time $t=0$. At this time shareholders privately communicate to the Board whether they wish them to maximise the long-run value of the firm, or to maximise the short-run $(t=1)$ share price. The Board privately observe the proportion $\alpha$ of shareholders who vote for $t=1$ share price maximisation. At the start of $t=1$ the Board use an objective function weighted $\alpha$ parts for short-term value maximisation and $1-\alpha$ for long-term value maximisation. The rest of the game remains unchanged.

The privacy of the communication between the shareholders and the Board captures that it is impossible for a shareholder to prove the absence of any communication with the Board, individual members of it, or with friends/colleagues of those members.

As we are exploring the pressures on an individual Board, we continue to use a partial equilibrium approach and so suppose that the market price of the productive asset is independent of this firm's actions at a level of $P$.

\subsection{Shareholder Voting And Board Objectives}

We solve the model by backward induction from the point at which the business decision is taken, $t=1$. Suppose the Board have received $\alpha$ votes in favour of short-term value maximisation. The Board's objective function at time $t=0$ can be written $V(\tau, \alpha)=$ $\alpha X_{1}+(1-\alpha) X_{2}(\tau)$ where $X_{1}$ is the expected value of the firm at the end of $t=1$, and $X_{2}(\tau)$ the expected $t=2$ value. The variable $X_{1}$ is not a function of the firm type as this will not have been revealed when the $t=1$ share-price is set.

Denote the market's expectation of the vote as $\tilde{\alpha}$. This expectation is a function of the publicly known proportion of the short-term shareholders, $L$, on the register.

Let us suppose that the Board elect to pursue the risky technology. The market would infer that types $[\tilde{\tau}, 1]$ would choose to develop the risky technology by Lemma 3 at the prevailing productive asset price of $P$. Hence, at the start of $t=1$, if they pursue the 
risky technology then the Board can expect their future share prices to be

$$
X_{1}=\int_{\tau=\tilde{\tau}}^{1} \frac{\bar{R}}{P} \tau \frac{g(\tau)}{1-G(\tilde{\tau})} d \tau \text { and } X_{2}(\tau)=\frac{\bar{R}}{P} \tau
$$

The Board of the lowest type $\tilde{\tau}$ receiving $\tilde{\alpha}$ votes for short run $(t=1)$ value maximisation must be indifferent between developing the technology and not. Hence the indifference condition for the Board is

$$
r=\tilde{\alpha} \int_{\tau=\tilde{\tau}}^{1} \frac{\bar{R} \tau}{P} \cdot \frac{g(\tau)}{1-G(\tilde{\tau})} d \tau+(1-\tilde{\alpha}) \frac{\bar{R} \tilde{\tau}}{P}
$$

This delivers the critical type $\tilde{\tau}$ which just opts for the risky technology as a function of the market beliefs of the voting, $\tilde{\alpha}$.

Now we move to the voting part at time $t=0$. The game is solved by the following Proposition:

Proposition 13 The unique pure strategy equilibrium of the shareholder voting game is for short-term shareholders to privately vote for share price maximisation, and long-term shareholders to vote for npv maximisation. The Board's objective function will be given by $\alpha=L$ so that $V(\tau, L)=L X_{1}+(1-L) X_{2}(\tau)$.

The short-term shareholders are in a prisoner's dilemma. Ex ante such shareholders prefer firms whose Boards maximise long-run value. However, once the short-term shareholder own the stock, if the firm pursues the safe technology it will be valued in the short-run at less than a firm which pursues the risky technology. Hence short-term shareholders always face an incentive to press for the risky technology to be adopted, no matter what the actual skill of the firm is. Hence these shareholders, in private, vote for short-term share price maximisation. The market correctly anticipates this incentive.

For long-term shareholders the incentives are different. Given the presence of some short-term shareholders, the market will infer that the Board will, to some extent, be internalising the path of the share price. Hence there exist border line firm types who would select the risky technology even though it is long term value reducing. Long-term shareholders wish to minimise these misallocation situations. They would therefore vote to pressure the Board to not focus on short-term share prices. This would bring the Board's decision making closer to their preferred ideal of long-run value maximisation. Hence long-term shareholders vote for a focus on the $t=2$ final value.

The resultant equilibrium is that short-term shareholders vote for short run share price maximisation, validating the objective function used in the benchmark model. 


\section{Conclusions}

A firm seeks to maximise the wealth of its existing shareholders. As shareholders differ in their investment horizons, this implies that the Board of a firm must be concerned with the path of the share price through time as well as with its final value. The shorter is the average time-horizon of the investors, the greater is the stress on short-term results. As a result having short-term shareholders on the register causes a firm to wish to take actions which pool it with firms of high value. Thus a firm which enters a high-risk/high-reward market will send a signal that the management believe they have a high quality firm which can make profits in this space. This desire to enter markets for the benefits of signalling drives up the price of the inputs needed to enter the market to above their fundamental levels. A bubble is created. Further, as the inputs are more expensive, firms must enter at a smaller scale than they would do otherwise. Market clearing then causes too many firms to self select into the high-risk/high-reward market. Thus short-term shareholders in an economy lead to bubbles, too many firms in risky markets, and so to a higher cost of capital for the sector.

Faced with some short-term shareholders on the register a Board must structure incentives of the CEO to ensure sufficient attention is paid to the path of the share price. This can be achieved by increasing the weighting on the short-run share price. However this encourages even weak firms to enter markets in which they are unlikely to make money. Further it does not strengthen the incentives to invest in the firm's capabilities as the share price is invariant to efforts the CEO makes to improve the long-run capabilities of the firm. Incentivising the CEO to exert effort on capability is expensive as the reward is risky, and so the risk averse CEO discounts it. Short-run shareholders gain less from the increase in the capabilities as it will not be factored into the share price in the short run, and yet they bear the costs. Hence as the proportion of short-term shareholders on the register increases, the CEO's incentive contract becomes overly weighted to short-term results, leading to too many firms opting for the high-risk/high-reward industry, with CEOs exerting less effort in making a long run success of the decision.

Finally we demonstrate that the Board's objective function is robust to shareholders' voting intentions. Ex ante all prospective shareholders can agree that they would rather a firm focuses on long run value maximisation. However once the shares are bought, an owner who will sell before payoffs are realised is in a prisoner's dilemma. Such a shareholder would in private gain by encouraging a firm to consider the path of the share price at the margin. In equilibrium this desire is internalised by the firm and by the market and so microfounds the results.

In principle, if a firm was unable to determine the time-horizon of its owners then the negative outcomes described here would be avoided. Thus, if investors all channeled their funds through a third party, such as a bank, and the bank(s) were the firm's only investors, 
then arguably the effects described here would not occur. Though the providers of capital may be subject to liquidity shocks, by pooling resources into a bank those liquidity shocks would not impact corporate decision making. Such a model of ownership is similar to the German and Japanese models of corporate control (Froot, Perold, and Stein (1992)). It is well known however that such an approach has its own disadvantages and so can be no panacea to the forces identified in this paper.

\section{A Omitted Proofs}

Proof of Lemma 1. Rewrite (4) as $r P^{f}=\bar{R} q\left(b P^{f}\right)$. The left hand side is increasing in $P^{f}$. The right hand side is declining in $P^{f}$. Hence any solution to (4) must be unique. We have $\lim _{P^{f} \rightarrow 0} \bar{R} q\left(b P^{f}\right)=\bar{R}>\left[r P^{f}\right]_{P^{f}=0}$ and $\lim _{P^{f} \rightarrow 1 / b}=0<\left[r P^{f}\right]_{P^{f}=1 / b}$ hence a fundamental price exists by the Intermediate Value Theorem.

Proof of Lemma 2. A proportion $1-L$ of the shareholders are long term investors. The Board would expect these to receive a payoff of $\Pi^{\text {risk }}(\tau)$ which will arrive at period $t=2$. The remaining $L$ of the shareholders will sell at the end of $t=1$. They will receive a price which depends upon the market's belief of the firm's type: $E\left(\Pi^{\text {risk }}(\tau) \mid \tau \in T^{\text {risk }}\right)$. Combining yields (5).

Proof of Lemma 3. Suppose otherwise that the Board's strategy was not a cut-off type of this form. Then there must exist two firm types $\tau_{1}<\tau_{2}$ such that a firm of type $\tau_{1}$ would strictly prefer to develop the risky technology whilst the firm with higher type $\tau_{2}$ would strictly prefer to develop the safe technology. Hence we would have

$$
V^{\text {risk }}\left(\tau_{1}, L\right)>r>V^{\text {risk }}\left(\tau_{2}, L\right)
$$

However, using Lemma 2 and (1)

$$
\begin{aligned}
\frac{\partial}{\partial \tau} V^{\text {risk }}(\tau, L) & =\frac{\partial}{\partial \tau}\left[(1-L) \Pi^{\text {risk }}(\tau)+L E\left(\Pi^{\text {risk }}(\tau) \mid \tau \in T^{\text {risk }}\right)\right] \\
& =(1-L) \bar{R}>0 \text { as } L<1
\end{aligned}
$$

However this contradicts (24). Therefore if type $\tau_{1}$ prefers to develop the risky technology so must all higher type firms.

Proof of Proposition 4. For market clearing (3), and using the cut-off property of Lemma 3, firms with type $\tau \in[q(b P), 1]$ will develop the risky technology. Each firm will buy $1 / P$ units of the productive asset. Applying Bayes rule, the expected value at end 
$t=1$ of a firm which develops the risky technology is

$$
\begin{aligned}
E\left(\Pi^{\text {risk }}(\tau) \mid \tau \in[q(b P), 1]\right) & =\int_{\tau=q(b P)}^{1} \frac{\bar{R} \tau}{P} \cdot \frac{1}{b P} g(\tau) d \tau \\
& =\frac{\bar{R}}{b P^{2}}\left\{q(b P) b P+\int_{\tau=q(b P)}^{1} 1-G(\tau) d \tau\right\}
\end{aligned}
$$

The last line follows by integration by parts. Market clearing requires that the firm of type $\tau=q(b P)$ to be indifferent between developing the risky technology and the safe technology. If the firm develops the safe technology then both long and short-term shareholders will secure profits of $r$. Using Lemma 2 and (25) we require:

$$
r=\left[(1-L) \frac{\bar{R} \tau}{P}+L \frac{\bar{R}}{b P^{2}}\left\{q(b P) b P+\int_{\tau=q(b P)}^{1} 1-G(\tau) d \tau\right\}\right]_{\tau=q(b P)}
$$

This can be simplified to yield (6). To show that we have a bubble, suppose for a contradiction that $P \leq P^{f}$. Then using (4), $\bar{R} q(b P) / P \geq r$ as $q(b P) / P$ is declining in $P$. Hence we must have the integral term in (6) being weakly negative which is a contradiction if $L>0$ as $P \leq P^{f}<1 / b$ by Lemma 1 . Hence $P>P^{f}$. Existence follows using the Intermediate Value Theorem on prices $P \in\{0,1 / b\}$, and using assumption (2).

For the final result note that firms of type $\tau \in[q(b P), 1]$ develop the risky technology, and as $P>P^{f}$ we have $q(b P)<q\left(b P^{f}\right)$. Hence an inefficiently large number of firms develop the risky technology.

Proof of Proposition 5. From (6) define the function $W(P):=\bar{R} q(b P) / P+$ $L\left(\bar{R} / b P^{2}\right) \int_{\tau=q(b P)}^{1} 1-G(\tau) d \tau$. The equilibrium price is defined implicitly, rewriting $(6)$ as $r=W(P)$. Hence the sensitivity of the market price to the proportion of short-term shareholders is $d P / d L=-(\partial W / \partial L) /(\partial W / \partial P)$. By inspection we see that $\partial W / \partial L>0$. For the denominator we explicitly find

$$
\frac{\partial W}{\partial P}=q^{\prime}(b P) b \frac{\bar{R}}{P}(1-L)-\bar{R} \frac{q(b P)}{P^{2}}-2 L \frac{\bar{R}}{b P^{3}} \int_{\tau=q(b P)}^{1} 1-G(\tau) d \tau<0
$$

where the inequality follows as $q^{\prime}(\cdot)<0$. Hence we have $d P / d L>0$.

The first result now follows immediately. For the second result market clearing has firms with type $\tau \in[q(b P), 1]$ developing the risky asset, and this range expands with the proportion of short-term shareholders. For the final result the expected payoff of a firm exploiting the risky technology is given by $\bar{R} \tau / P$. Hence the average such expected payoff conditional on developing the risky technology is $\int_{\tau=q(b P)}^{1} \frac{\bar{R} \tau}{P} \frac{1}{b P} g(\tau) d \tau$. We can rewrite this as

$$
\text { Average payoff from risky technology }=\frac{\bar{R}}{P} \cdot \frac{\int_{\tau=q(b P)}^{1} \tau g(\tau) d \tau}{\int_{\tau=q(b P)}^{1} g(\tau) d \tau}
$$


Now note that

$$
\begin{aligned}
& \frac{d}{d P}\left\{\frac{\int_{\tau=q(b P)}^{1} \tau g(\tau) d \tau}{\int_{\tau=q(b P)}^{1} g(\tau) d \tau}\right\} \\
= & \operatorname{sign} \underbrace{-q^{\prime}(b P)}_{\text {+ve }} b g(q(b P))\left\{q(b P) \int_{\tau=q(b P)}^{1} g(\tau) d \tau-\int_{\tau=q(b P)}^{1} \tau g(\tau) d \tau\right\} \\
= & \operatorname{sign} \int_{\tau=q(b P)}^{1}(q(b P)-1) g(\tau) d \tau<0
\end{aligned}
$$

As $d P / d L>0$, it follows from (26) that the average payoff from the risky technology falls with the price of the productive asset. Hence we have the final result.

Proof of Proposition 6. The expected value of a firm of unknown type to long term shareholders is

$$
V=\int_{\tau=0}^{q(b P)} r g(\tau) d \tau+\int_{\tau=q(b P)}^{1} \frac{\bar{R}}{P} \tau g(\tau) d \tau
$$

We now establish that short-term shareholders share the same valuation. If the firm develops the safe technology then there is no uncertainty. If the firm develops the risky technology then at $t=1$ the firm will be valued at $\int_{\tau=q(b P)}^{1} \frac{\bar{R}}{P} \tau \frac{g(\tau)}{b P} d \tau$. At time $t=0$, the probability of lying in the range $[q(b P), 1]$ is $b P$ by definition of $q(\cdot)$. Hence $(27)$ applies.

Now we establish $d V / d L$ by implicit differentiation of (27):

$$
\frac{d V}{d L}=\frac{d P}{d L} \cdot\left\{\begin{array}{c}
q^{\prime}(b P) b g(q(b P))\left[r-\frac{\bar{R}}{P} q(b P)\right] \\
-\int_{\tau=q(b P)}^{1} \frac{\bar{R}}{P^{2}} \tau g(\tau) d \tau
\end{array}\right\}
$$

By Proposition $4 P>P^{f}$, and so from $(4) r>\bar{R} q(b P) / P$. As $q^{\prime}(\cdot)<0$ and $d P / d L>0$ (Proposition 5), we have $d V / d L<0$ as required. Hence a greater proportion of short-term shareholders raises the firm cost of capital.

Proof of Lemma 8. Substituting (9) into (8) delivers the CEO's utility from pursuing the risky technology as

$$
U^{\text {risk }}(f, b, v)=f+b \int_{T=\tilde{T}}^{\infty} \frac{\bar{R}}{P} T d \Gamma(T)+v \frac{\bar{R} \tau}{P}+\frac{1}{2}\left(\frac{\bar{R}}{P}\right)^{2} \frac{v^{2}}{\kappa}-\frac{\rho}{2} v^{2} \sigma^{2}
$$

If the CEO decides to invest in the safe technology then, as CEO effort on the risky technology cannot increase the safe payoff, the CEO would select $\eta=0$, and the $t=2$ payoff will be $r$. Given the certainty the $t=1$ share price will also be $r$. The CEO's pay will therefore be $f+r(b+v)$. As there is no uncertainty here, the utility of the CEO from the safe choice, is given by $U^{\text {safe }}=f+r(b+v)$. Comparing this to (28) yields (10).

The participation constraint for the CEO is that the expected utility, (28), exceeds $u$. This delivers (11). 
Proof of Proposition 9. Suppose the firm is of type $\tau$. If the Board decide to incentivise the risky technology they must maximise (12). This is a negative quadratic in $v$. Ignoring the incentive compatibility constraint (10), the first order condition for the optimisation of (12) with respect to $v$ yields (14). Lemma 7 delivers the CEO's effort choice as (15). Substituting into (12), the payoff of the Board is given by

$$
V^{\text {risk }}(\tau)=\frac{\bar{R}}{P} \tau+\frac{\left(\frac{\bar{R}}{P}\right)^{2} \frac{1}{\kappa}}{2\left[1+\left(\frac{P}{\bar{R}}\right)^{2} \kappa \rho \sigma^{2}\right]}-u
$$

Finally we check the constraints. Given the optimal long run incentive, $v$, (14), the incentive compatibility constraint (10) gives a lower bound on $b$ of

$$
b\left[\int_{T=\tilde{T}}^{\infty} \frac{\bar{R}}{P} T d \Gamma(T)-r\right] \geq \frac{r-\frac{\bar{R} \tau}{P}}{1+\left(\frac{P}{\bar{R}}\right)^{2} \kappa \rho \sigma^{2}}-\frac{\frac{1}{2}\left[\left(\frac{\bar{R}}{P}\right)^{2} \frac{1}{\kappa}-\rho \sigma^{2}\right]}{\left[1+\left(\frac{P}{\bar{R}}\right)^{2} \kappa \rho \sigma^{2}\right]^{2}}
$$

The right hand side is decreasing in $\tau$. Note that $\tilde{T}=\tilde{\tau}+\eta^{*}>r P / \bar{R}$ and so $\int_{T=\tilde{T}}^{\infty} \frac{\bar{R}}{P} T d \Gamma(T)>r$. Therefore a positive bonus is required if

$$
r-\frac{1}{2} \frac{\left[\left(\frac{\bar{R}}{P}\right)^{2} \frac{1}{\kappa}-\rho \sigma^{2}\right]}{\left[1+\left(\frac{P}{\bar{R}}\right)^{2} \kappa \rho \sigma^{2}\right]}>\frac{\bar{R} \tau}{P}
$$

Algebraic manipulation yields (16). Finally set $b$ to the lower bound, or 0 if the bound is negative, and substitute for $b$ and $v$ into the participation constraint (11). The fixed fee can be lowered to satisfy this constraint with equality. Hence the unconstrained optimisation also satisfies the constraint (10).

If instead the Board could seek the safe technology then they can lower their payments to the minimum level of $u$ by setting $f=u$ and secure a value of $V^{\text {safe }}=r-u$. The Board will prefer risky technology if $V^{\text {risk }}(\tau)>V^{\text {safe }}(\tau)$. This yields (13).

Proof of Proposition 10. The fixed fee can be lowered until (11) is satisfied with equality, and using (9), we have the Board's objective value from incentivising the risky technology as

$V^{\mathrm{risk}}(b, v ; \tau)=L \int_{T=\tilde{T}}^{\infty} \frac{\bar{R}}{P} T d \Gamma(T)+(1-L) \frac{v}{\kappa}\left(\frac{\bar{R}}{P}\right)^{2}+(1-L) \frac{\bar{R}}{P} \tau-\frac{1}{2}\left(\frac{\bar{R}}{P}\right)^{2} \frac{v^{2}}{\kappa}-\frac{\rho}{2} v^{2} \sigma^{2}-u$

This must be solved subject to the incentive compatibility constraint (10). Equation (29) is the parallel of (12) and is again a negative quadratic in $v$. Hence, ignoring for the moment the constraint (10) and optimising, the Board, if they choose the risky technology, 
will select the long-term incentive (20). The CEO will therefore improve the firm's type by $\eta^{*}$, given by (9) and yielding (21).

The payoff to the Board of developing the risky technology is given by substituting (20) into (29) to yield

$$
V^{\mathrm{risk}}(\tau)=L \int_{T=\tilde{T}}^{\infty} \frac{\bar{R}}{P} T d \Gamma(T)+(1-L) \frac{\bar{R}}{P} \tau+\frac{(1-L)^{2} \frac{1}{2}\left(\frac{\bar{R}}{P}\right)^{2} \frac{1}{\kappa}}{\left[1+\left(\frac{P}{\bar{R}}\right)^{2} \kappa \rho \sigma^{2}\right]}-u
$$

If the Board instead opt for the safe technology they can pay the CEO $f=u$ and so they would have a payoff of $r-u$. Hence the Board is indifferent between the two courses of action at type $\tilde{\tau}$ given by (19). It must be that the market correctly infer this condition in equilibrium. Hence in equilibrium all firms of type $\tau \in[\tilde{\tau}, \infty)$ will develop the risky technology. The distribution of firms which develop the risky technology is therefore supported on $\tilde{T} \in\left[\tilde{\tau}+\eta^{*}, \infty\right)$ with $\eta^{*}$ given by (21), and the distribution function given by $\Gamma(T)=\frac{G\left(T-\eta^{*}\right)}{1-G(\tilde{\tau})}$. Equation (19) follows.

Proof of Proposition 11. Results 2 and 3 follow by inspection of (20) and (21). The critical firm type is given implicitly by $\tilde{\tau}(L)$ in $(19)$. Implicitly differentiating with respect to $L$ we have

$$
\begin{aligned}
0= & \int_{\tau=\tilde{\tau}}^{\infty} \frac{\bar{R}}{P}\left(\tau+\eta^{*}\right) \frac{g(\tau)}{1-G(\tilde{\tau})} d \tau+L \int_{\tau=\tilde{\tau}}^{\infty} \frac{\bar{R}}{P} \frac{d \eta^{*}}{d L} \frac{g(\tau)}{1-G(\tilde{\tau})} d \tau-\frac{\bar{R}}{P} \tilde{\tau}-\frac{(1-L)\left(\frac{\bar{R}}{P}\right)^{2} \frac{1}{\kappa}}{\left[1+\left(\frac{P}{\bar{R}}\right)^{2} \kappa \rho \sigma^{2}\right]} \\
& +\frac{d \tilde{\tau}}{d L}\left\{\frac{g(\tilde{\tau})}{1-G(\tilde{\tau})} L \frac{\bar{R}}{P}\left[\int_{\tau=\tilde{\tau}}^{\infty}\left(\tau+\eta^{*}\right) \frac{g(\tau)}{(1-G(\tilde{\tau}))} d \tau-\left(\tilde{\tau}+\eta^{*}\right)\right]+(1-L) \frac{\bar{R}}{P}\right\}
\end{aligned}
$$

The brace is positive. Hence the sign of $d \tilde{\tau} / d L$ is given by the opposite of that of the top line. Multiplying through by $L$ and then simplifying using (19) yields

$$
\begin{aligned}
\frac{d \tilde{\tau}}{d L} & =\operatorname{sign}(1-L) \frac{\bar{R}}{P} \tilde{\tau}+\frac{(1-L)^{2} \frac{1}{2}\left(\frac{\bar{R}}{P}\right)^{2} \frac{1}{\kappa}}{\left[1+\left(\frac{P}{\bar{R}}\right)^{2} \kappa \rho \sigma^{2}\right]}-L^{2} \frac{\bar{R}}{P} \frac{d \eta^{*}}{d L}+L \frac{\bar{R}}{P} \tilde{\tau}+L \frac{(1-L)\left(\frac{\bar{R}}{P}\right)^{2} \frac{1}{\kappa}}{\left[1+\left(\frac{P}{\bar{R}}\right)^{2} \kappa \rho \sigma^{2}\right]}-r \\
& =\frac{\bar{R}}{P} \tilde{\tau}+\frac{\left(\frac{\bar{R}}{P}\right)^{2} \frac{1}{\kappa}}{\left[1+\left(\frac{P}{\bar{R}}\right)^{2} \kappa \rho \sigma^{2}\right]} \frac{1}{2}\left(1+L^{2}\right)-r \text { after differentiating }(21) \\
& =L\left[\frac{\bar{R}}{P} \tilde{\tau}+\frac{\left(\frac{\bar{R}}{P}\right)^{2} \frac{1}{\kappa}}{\left[1+\left(\frac{P}{R}\right)^{2} \kappa \rho \sigma^{2}\right]}-\int_{\tau=\tilde{\tau}}^{\infty} \frac{\bar{R}}{P}\left(\tau+\eta^{*}\right) \frac{g(\tau)}{1-G(\tilde{\tau})} d \tau\right] \mathrm{using}(19) \\
& =L\left[\frac{\bar{R}}{P}\left(\tilde{\tau}+\eta^{*}\right)-\int_{\tau=\tilde{\tau}}^{\infty} \frac{\bar{R}}{P}\left(\tau+\eta^{*}\right) \frac{g(\tau)}{1-G(\tilde{\tau})} d \tau\right] \\
& <0
\end{aligned}
$$


This yields the first result that increasing $L$ lowers the type of firm for which the Board will incentivise the risky technology.

Proof of Proposition 13. Consider first short-term shareholders. If the Board pursue the risky technology then the expected market price will be $X_{1}$ as given in (22), otherwise the market price will be $r$. We first show that the market price at end $t=1$ is higher if the Board pursue the risky technology. We have

$$
X_{1}=\int_{\tau=\tilde{\tau}}^{1} \frac{\bar{R} \tau}{P} \frac{g(\tau)}{1-G(\tilde{\tau})} d \tau>\frac{\bar{R} \tilde{\tau}}{P} \cdot \int_{\tau=\tilde{\tau}}^{1} \frac{g(\tau)}{1-G(\tilde{\tau})} d \tau=\frac{\bar{R} \tilde{\tau}}{P}
$$

So $X_{1}>\tilde{\alpha} \int_{\tau=\tilde{\tau}}^{1} \frac{\bar{R}}{P} \tau \frac{g(\tau)}{1-G(\tilde{\tau})} d \tau+(1-\tilde{\alpha}) \bar{R} \tilde{\tau} / P=r$, where the final equality is (23). It follows that short-term shareholders will vote for the action which increases the likelihood of the risky technology being pursued.

We now confirm that voting for short-term value maximisation makes the Board more likely to pursue the risky technology. Given market beliefs $\tilde{\alpha}$ and $\tilde{\tau}$, the Board in receipt of $\alpha$ votes for short-term value maximisation will pursue the risky technology if its type lies in $[\tau(\alpha), 1]$ where

$$
r=\alpha \underbrace{\int_{\tau=\tilde{\tau}}^{1} \frac{\bar{R}}{P} \tau \frac{g(\tau)}{1-G(\tilde{\tau})} d \tau}_{X_{1}}+(1-\alpha) \underbrace{\bar{R} \tau(\alpha) / P}_{X_{2}(\tau(\alpha))}
$$

To evaluate how extra votes for short-termism would affect the critical firm type $\tau(\alpha)$, differentiate (30) with respect to $\alpha$ and evaluate at $\alpha=\tilde{\alpha}$. We establish that

$$
\begin{aligned}
0 & =\int_{\tau=\tilde{\tau}}^{1} \frac{\bar{R}}{P} \tau \frac{g(\tau)}{1-G(\tilde{\tau})} d \tau-\frac{\bar{R}}{P} \tilde{\tau}+\tau^{\prime}(\tilde{\alpha})(1-\tilde{\alpha}) \frac{\bar{R}}{P} \\
& =\frac{1}{\tilde{\alpha}}\left[r-\frac{\bar{R} \tilde{\tau}}{P}\right]+\tau^{\prime}(\tilde{\alpha})(1-\tilde{\alpha}) \frac{\bar{R}}{P} \operatorname{using}(23)
\end{aligned}
$$

It follows that $\tau^{\prime}(\tilde{\alpha})<0$ as $r>\bar{R} \tilde{\tau} / P$ from (23). Combining short-term shareholders wish the firm to pursue the risky technology, and the probability of this occurring increases if the short-term shareholders vote for short-term share price maximisation.

Now consider long-term shareholders. If the Board pursue the risky technology then the profits realised will be $\bar{R} \tau / P$ which depend upon the true type of the firm. If the Board pursue the safe technology then the profits realised will be $r$. If the shareholders vote in proportion $\alpha$ for the short-term share price then types $[\tau(\alpha), 1]$ will develop the risky technology. Hence the long term shareholders will secure value $G(\tau(\alpha)) r+$ $\int_{\tau=\tau(\alpha)}^{1} \frac{\bar{R}}{P} \tau g(\tau) d \tau$. The marginal firm type is given by (30). We established above that $\tau^{\prime}(\tilde{\alpha})<0$. Hence increasing $\alpha$ above its expected level lowers the long-term shareholders value as $r>\frac{\bar{R}}{P} \tilde{\tau}$ from (23). This demonstrates that long-term shareholders will vote for long-term value maximisation. 
In equilibrium the market must correctly anticipate the shareholders' votes. Hence $\alpha=\tilde{\alpha}=L$.

\section{References}

[1] Allen, Franklin, and Doublas Gale, 2007, Understandng Financial Crises, Oxford University Press.

[2] Allen, Franklin, and Douglas Gale, 2000, Crises and Bubbles, Economic Journal, 110, 236-255.

[3] Allen, Franklin, and Gary Gorton, 1993, Churning Bubbles, Review of Economic Studies, 60, 813-836.

[4] Allen, Franklen, Stephen Morris, and Andrew Postlewaite, 1993, Journal of Economic Theory, 61, 206-229.

[5] Asker, John, Joan Farre-Mensa, and Alexander P. Ljungqvist, 2010, Does the Stock Market Harm Investment Incentives?, CEPR Discussion Paper DP7857.

[6] Aspen Institute, 2009, Overcoming Short-termism: A Call for a More Responsible Approach to Investment and Business Management, Aspen Institute, New York.

[7] Bebchuk, Lucian, and Lars Stole, 1993, Do short-term objectives lead to under or overinvestment in long-term projects, Journal of Finance, 48, 719-729.

[8] Bhattacharya, Sudipto, 1979, Imperfect Information, Dividend Policy, and "The Bird in the Hand" Fallacy, Bell Journal of Economics, 10, 259-270.

[9] Bolton, Patrick, Jose Scheinkman, and Wei Xiong, 2006, Executive Compensation and Short-Termist Behaviour in Speculative Markets, Review of Economic Studies, 73, 577-610.

[10] Bushee, Brian, 1998, The influence of institutional investors on myopic R\&D investment behavior, Accounting Review 73, 305-333.

[11] Chen, Xia, Jarrad Harford, and Kai Li, 2007, Monitoring: Which institutions matter?, Journal of Financial Economics 86, 279-305.

[12] Camerer, Colin, 1989, Bubbles and Fads in Asset Prices: A Review of Theory and Evidence, Journal of Economic Surveys, 3, 3-41

[13] DeAngelo, Harry, 1981, Competition and Unanimity, American Economic Review, $71,18-27$.

[14] Derrien, Francois, Ambrus Kecskes, and David Thesmar, forthcoming, Investor Horizons and Corporate Policies, Journal of Financial and Quantitative Analysis.

[15] Edmans, Alex, Xavier Gabaix, Tomasz Sadzik and Yuliy Sannikov, 2012, Dynamic CEO Compensation, Journal of Finance, 67, 1603-1647.

[16] Fisher, Irving, 1930, The Theory of Interest, New York.

[17] Froot, Kenneth, Andre Perold, and Jeremy Stein, 1992, Shareholder Trading Practices and Corporate Investment Horizons, Journal of Applied Corporate Finance, 5, $42-58$.

[18] Gaspar, Jose-Miguel, Massimo Massa, and Pedro Matos, 2005, Shareholder investment horizons and the market for corporate control, Journal of Financial Economics $76,135-165$. 
[19] Goldman, Eitan, and Gunter Strobl, 2013, Large Shareholder Trading and Complexity of Corporate Investments, Journal of Financial Intermediation, 22, 106-122.

[20] Graham, John, Campbell Harvey, and Shiva Rajgopal, 2005, The economic implications of corporate financial reporting, Journal of Accounting and Economics 40, $3-73$.

[21] He, Zhiguo, 2012, Dynamic Compensation Contracts with Private Savings, Review of Financial Studies, 25, 1494-1549.

[22] Miller, Merton, 1977, Debt and Taxes, Journal of Finance, 32, 261-275.

[23] Miller, Merton, and Kevin Rock, 1985, Dividend policy under asymmetric information, Journal of Finance, 40, 1031-1051

[24] Myers, Stewart, 1984, The Capital Structure Puzzle, Journal of Finance, 39, 575-592.

[25] Myers, Stewart, and Nicholas Majluf, 1984, Corporate financing and investment decisions when firms have information that investors do not have, Journal of Financial Economics, 13, 187-221.

[26] Polk, Christopher, and Paola Sapienza, 2009, The stock market and corporate investment: A test of catering theory, Review of Financial Studies 22, 187-217.

[27] Shleifer, Andrei, and Robert Vishny, 1990, Equilibrium short horizons of investors and firms, American Economic Review 80, 148-153.

[28] Stein, Jeremy, 2003, Agency, information and corporate investment, in Constantinides, G., M. Harris and R. Stulz, eds., Handbook of the Economics of Finance (New York, Elsevier).

[29] Stein, Jeremy, 1996, Rational capital budgeting in an irrational world, Journal of Business 69, 429-455.

[30] Stein, Jeremy, 1989, Efficient capital markets, inefficient firms: A model of myopic corporate behavior, Quarterly Journal of Economics 104, 655-669

[31] Thanassoulis, John, forthcoming, Industry Structure, Executive Pay, and ShortTermism, Management Science.

[32] Varian, Hal, 1992, Microeconomic Analysis, W.W.Norton and Company Inc. 